\title{
The Quality Assessment of Clinical Teaching System Based on Legal Construction
}

\author{
Kaijian Hou, Xuhuang Wang, Chuangjian Lin, Yinghua Yao, Bangtai Wu, Dan \\ Zhu, Chao Chen*
}

Shantou City Affiliated Hospital of Guangzhou Chinese Medicine University, Shantou, Guangdong Province, China, 515000

hunter2011@foxmail.com

Keywords: Quality Assessment, Clinical Teaching System, Legal Construction

\begin{abstract}
Medicine is a very practical science. In medical education, clinical teaching stage is a critical period to develop clinical competence and professional ethics formation for the students. The paper discusses legal issues and improvement strategy in clinical medical education, it has a positive effect on ensuring the quality of clinical teaching with legal norms, protecting the legitimate interests of the teachers, students and the patients.
\end{abstract}

\section{Introduction}

In fully implement the Party Central Committee and the State Council, under the new situation, "education" and "rule of law" strategy, we usher in the new challenges of the 21 st century higher education, particularly medical clinical education, medicine is a very practical science in medical education, clinical teaching professional stage for the students to learn, develop clinical competence, ethics formation is a critical period, Affiliated Hospital of Medical Colleges, bears clinical teaching from theory to practice, the whole process is talent, an important stage of the product [1]. The "Medical Practitioners" "University Undergraduates Teaching Assessment Programme" "Students equity method" and other laws and regulations formulated specifically to participate in clinical teaching of each subject, have a separate, legitimate interest demands, such as a patient medical safety, privacy, informed consent, students in medical practice as the core of the right to education, with a teacher's teaching authority, etc. Traditional medical technology with traditional teaching model, not a good deal and face a wide range of complex relationships and interests involved in clinical teaching, often clinical teaching of violations and disputes, affecting the quality of teaching, by exploring the clinical education legal problems and improvement strategy, clinical teaching with legal norms to ensure the quality of clinical teaching, to protect the patient, with the legitimate interests of the teachers to teach and students have a positive effect. Therefore, the Ministry of Education to implement "a number of opinions on the overall improving the quality of higher education," the spirit of our research work in line with the rule of law Construction of clinical teaching quality monitoring system, not only to achieve the purpose of teaching, clinical teaching work to improve quality control at the same time, also enhanced with a teacher and medical students in administrative regulations involving health behaviors and awareness, so that clinical teaching job in line with my party to further the implementation of the process of building the rule of law, so that clinical teaching work more scientific.

\section{The Necessity of Establishment of Clinical Teaching Quality Assessment System}

With the development of domestic higher medical education, expansion of enrollment, clinical teaching is facing great challenges. In the current economic and social situation, the traditional way of teaching has been some impact. Clinical teachers who are charged with health care, teaching, research triple mission, heavy medical and scientific research, light teaching is common. The competition for jobs after enrollment brought medical students during their clinical practice while facing the dual pressures of work and study section to find, the students put into practice reduced; the 
legal community continue to improve, the patient with the legal weapons to protect their own privacy sick, medical students clinical training and hands-on opportunities to reduce; doctor-patient conflicts intensified, enhanced sense of responsibility clinicians saving lives, but also to reduce the chance of medical students hands. Enthusiasm and initiative of these factors influence medical students' clinical practice, thus nurturing clinical skills operational capability has also been varying degrees of impact, the quality of clinical teaching a certain degree of decline. Although there is a fine tradition clinical teaching, clinical teaching experience, but has not yet formed a relatively complete system of teaching quality assessment. Therefore, in order to further improve and stabilize clinical teaching quality, according to the Ministry of Education, Ministry of Health requested specification clinical teaching, and better meet the undergraduate teaching level evaluation, it is necessary to establish and improve the clinical teaching quality assessment system.

\section{The Background of Construction of Clinical Teaching Quality Monitoring System}

In 2003, the World Federation of Medical Education (World Federation for Medical Education, WFME) announced the "Undergraduate Medical Education Global Standards", China closely follow the international trend, began to explore the localization of international standards of medical education research, in September 2008, education Ministry of Health jointly issued the "Chinese undergraduate medical education standards - clinical medicine specialty (Trial) teach high on the 9th, 2008," [2].

Currently a large number of clinical teaching of the relevant administrative regulations. "People's Republic of China on Medical Practitioners" "University Undergraduates Teaching Assessment Programme" "Students equity method" "Rules medical institution regulations" "Hospital System," "Hospital staff responsibilities," "People's Republic of China Civil Law" "Tort Liability Act" and other laws and regulations take almost a hundred, how to reconcile the contradictions clinical teaching and legal regulations, is very challenging.

\section{The Analysis of Factors Affecting Clinical Teaching Quality}

Medical students, especially medical students in clinical skills has become a common problem of the low level of medical students, first and foremost to teachers, students of medical education basic law of a certain lack of understanding about the heavy teaching theory, light practice teaching; secondly with large domestic medical market environment, when a new "Medical Practitioners" and other regulations enacted to enhance the patient's self-protection awareness, students in clinical internship process has little chance to direct patients to the clinical diagnosis and treatment operations, in addition to the above two objective factors, the most important clinical impression of the quality of teaching hospitals of five factors is the degree of attention to clinical teaching and management, clinical training base construction, teaching quality, teacher quality, student clinical practice enthusiasm and seriousness on [3]

\section{The Establishment of of Clinical Teaching Quality Monitoring System.}

Monitoring target clinical teaching quality monitoring system for clinical teaching base (Department), with a teacher, the students three main, these three subject of monitoring, evaluation, feedback, improvement constitute a clinical teaching quality monitoring system. Vice president of the hospital business, led places - Science and Education Division of the main governing body - each teaching base (Department) Teaching Secretary - Secretary of the clinical departments teaching full-time with a teacher - medical students as vertical lines management mechanism Work program.

The standards and monitoring system of clinical teaching bases (Department). According to "ordinary higher medical education clinical teaching base management Interim Provisions (teaching high [1992.8 Number])" document, referring to the province about the teaching hospital accreditation standards, the development of teaching bases State Education Commission, Ministry of Health and 
the State Administration of Traditional Chinese Medicine jointly issued rating quality standards, including the Department of the teaching hospital accreditation standards, the development of teaching base evaluation quality standards, including the three-level indicators teaching conditions, teaching management, teaching facilities.

Organized by the hospital has clinical experience and teaching experience in the professional composition of the Steering Group in conjunction with the science and education department secretary and teaching hospitals to regularly teaching base (Department) guidance and assessment. The main content of teaching rounds, teaching base evaluation, set up to review the level of the base have not yet reached the standard of teaching (Department), to take measures to rectification period after re-evaluation, re-evaluation were still not up to standard, and the end of the year award from the department in charge of hospital departments, promotion and other personnel associated with the hook, or even cancel their teaching qualifications.

The quality standards and monitoring system of teachers. Clinical Tutors main request titles in education and other basic conditions, while developing teaching evaluation system of teachers from the clinical level, teaching level, teaching attitude, etc., to establish hospitals, teaching base (Department), students with tertiary education teacher evaluation system.

According to the standard, the base hospital appointment (Department) with a teacher, to provide reasonable remuneration, will work with the titles of teaching appointment hook. The local employment base with regular education teachers training and experience-sharing sessions held. On the one hand to improve clinical teachers teaching costs; on the other hand provide free education clinical teaching teachers, recommended papers published favorable conditions for cooperation and scientific research, mobilize clinical teachers teach with enthusiasm.

The quality standards and monitoring system of students. Student evaluation quality standards established primarily by the medical students training objectives, referring to the requirements of clinical practitioners to develop clinical practice syllabus, according to the outline requirements for different stages of the assessment.

Student assessment and quality control including disciplinary learning quality monitoring two aspects. Disciplinary control room a hierarchical management process, learning is primarily an export quality control management, through $3+1+1$ assessment program to ensure " 3 " refers to the practice of the process of the hospital three times a chronological assessment, including pre-job evaluation the mid-assessment and graduation examination. The first "1" refers to the process through the practice of departmental rotation examination, the second " 1 " refers to the medical record writing assessment, not by every aspect, can not enter the next stage of internships. [3]

Medical students entering medical institution solemn oath moment already know, the medical profession is to save lives, relieve pain of humanity, is the implementation of revolutionary humanitarianism, in the treatment process, to recognize the basic elements of their medical profession, including the basic code of ethics, ethical principles and legal responsibilities, so as to nurture their pursuit of the correct professional values, with excellence, altruism, responsibility, compassion, responsibility, honesty, integrity and rigorous scientific attitude, let them feel the sacred and the value of the medical profession. [4]

\section{The Supervision and Regulation of Teaching Quality}

The monitoring mode of teaching quality. Construction of "unification, two, three steps, four body rings" is more complete, teaching quality monitoring system framework of science, namely unified teaching quality monitoring in order to ensure and improve the quality of teaching and training of qualified professionals for the final purpose; secondary school is the quality of teaching hospitals to implement hospital-level and scientific management and operation of indoor levels, three steps to the goal, the full name of the monitoring process and results; four-body system is the quality of teaching objectives, teaching quality assessment system, teaching quality information gathering feedback system, teaching quality guarantee system; rings is teaching objectives, teaching process, learning quality, quality of management, teaching and teaching building protection. 
The reflection of the laws and regulations in clinical teaching monitoring system. The rule of law is in accordance with the law reflects the will of the people and social development of the law governing the country, rather than in accordance with the personal will, advocate govern the country; for political, economic operation of all aspects of social activities in accordance with national law, and without any personal will intervention, impede or destroy. [5] In short, the rule of law is in accordance with the law to govern the country, the Communist Party of China leads the people is the basic strategy of the country, is an objective need to develop the socialist market economy, but also an important symbol of social progress, stability of the state is still important protection. In this stage of clinical teaching, but also always reflects the importance of laws and regulations.

Combined with teaching about the clinical course of the subject and body of laws and regulations involved in teaching behavior, the patient's right to medical safety, privacy, informed consent, students in medical practice as the core of the right to education, teaching with the teacher's right to teach and so on, establish a sound file and provisions of the process, such as patient teaching work as a signed informed consent of patients, for the protection of patient privacy, and in teaching process, the patient's right to medical safety protection at work teaching; student teaching work, teaching work to make a written response evaluation as a teaching base year quarterly (Department) and clinical departments for teacher evaluation system, an important part, as with a teacher of students with teach technical problems, the attitude of neglect teaching questions arise, image problems, you should be warned, or even abolish the teaching qualifications, may stay its professional and technical advancement and bonus distribution reduction if necessary; respect the rights and obligations of teaching teachers, refer to "teacher Law "to perform, and to participate in clinical teaching of medical personnel, appropriate economic compensation, also appraised and promotion a priority, and each quarter, each school year, by the hospital, teaching Base (Department) and clinical departments, selected outstanding teaching secretary and with a teacher, and give notice of commendation and reward.

\section{Conclusion}

Clinical medical teaching is a very important part of medical education process. The quality of clinical teaching quality has a direct relationship with training personnel. In such a society ruled by law, construct the clinical teaching quality monitoring system in line with the rule of law can not only strengthen the tracking and evaluation of clinical teaching, strengthen the daily management of clinical teaching, further improve the quality of clinical teaching, but also enhance the behaviors and awareness of teacher and medical students in administrative regulations. In this way, the clinical teaching job will be in line with the further implementation of legal construction, so that clinical teaching work will be more scientific.

\section{Acknowledgements}

This paper belongs to the The Quality Assessment of Clinical Teaching System Based on Legal Construction and clinical teaching base Teaching Reform project approval in 2014(2014JDB089, 2014 / 06-2016 / 06) which belongs to the Guangdong Education Department

\section{References}

[1] Q. Gao, Z.R.Lv, Clinical Teaching Problems and Reflections, J. Northwest Medical Education , $12(2008) 58-61$.

[2] L. Huang, L.M. Cheng, The recommendation and application of clinical teaching and Internal Quality Assurance System, J. China Higher Medical Education, 6(2012) 28-35.

[3] Y.Shi, L.Chen, The quality monitoring system of Chinese medicine clinical teaching, J. Chinese Education 4(2007) 129-132. 
[4] C.Chen, K. J. Hou, The teaching experience of improving the comprehensive ability of medical students. J. Chinese Medicine, 9 (2009) 19-22.

[5] W. Liao, Eighteen report put the "rule of law" mentioned in the strategy to new heights, J. Xinhua News Agency. 12(2009) 56-58. 